\title{
The Suffering of Invertebrates: An Approach from Animal Ethics
}

\author{
El sufrimiento de los invertebrados: una \\ aproximación desde la ética animal
}

\author{
Alejandro Villamor Iglesias \\ Instituto de Educación Secundaria \\ Carmen Martín Gaite \\ España \\ alejandrovillamoriglesias@yahoo.es \\ https://orcid.org/0000-0001-7265-7528
}

Recibido: 03 - 07 - 2019.

Aceptado: 16 - 10 - 2019.

Publicado en línea: 23-06-2021. 


\begin{abstract}
Invertebrate animals are usually seen as a kind of "aliens" which do not deserve any moral consideration. However, there is a growing amount of evidence indicating that many of them do have the capacity to experience pain. The same criteria that are usually applied in order to infer that vertebrates are sentient beings (behavioral response, learning capacity, memory, a certain specific neurophysiological structure...) lead to the idea that many invertebrates are sentient as well. Therefore, under the skeptical premise that we have no direct evidence of the experience of pain in vertebrates, we are forced to hold that it exists in both vertebrates and invertebrates.

Keywords: sentience; nociception; invertebrate suffering; antispeciesism.
\end{abstract}

\title{
Resumen
}

Los animales invertebrados son comúnmente vistos como una suerte de "aliens" que no merecen ninguna consideración moral. No obstante, una creciente cantidad de evidencias nos indica que muchos de ellos poseen la capacidad de experimentar dolor. Los mismos criterios que son normalmente empleados para inferir que los vertebrados son seres sintientes (respuesta conductual, capacidad de aprendizaje, memoria, una estructura neurofisiológica concreta...) nos conducen a la idea de que muchos invertebrados son igualmente sintientes. Por ende, bajo la premisa escéptica de que no tenemos ninguna evidencia directa de la experiencia del dolor en vertebrados, estamos forzados a mantener que ésta existe tanto en vertebrados como en invertebrados.

Palabras clave: sintiencia; nocicepción; sufrimiento de los invertebrados; antiespecismo. 


\section{Introduction $^{1}$}

Invertebrates represent between 90\% (Horvath et al., 2013) and 99\% (Carere et al., 2011) of the species of the animal kingdom, and their number in terms of individuals is much higher than that of vertebrates. Invertebratesinclude several types of phyla, such as arthropods(including insects), mollusks such as cephalopods, nematodes, or echinoderms. However, the question whether they should be morally considered is rarely addressed. Although the number of works related to this issue has increased over the last years (cfr., for example: Lockwood, 1988; Crook \& Walters, 2011; Broom, 2013; Tomasik, 2016d [2015] or Knutsson, 2016), the moral consideration of invertebrates is still an important field of animal ethics which remains largely unexplored. The main reason for this seems to be the relatively widespread view of invertebrates as a kind of "aliens" (Lockwood, 2014). Due to this, they are seldom seen as beings with interests, and when they are, there is a tendency to think that those interests do not deserve any consideration. Nevertheless, an increasing amount of research supports the view that invertebrates, or at least a large part of them, have the capacity to experience pain. Thus, if the capacity to have positive and negative experiences or, in other words, sentience, is accepted as a criterion of moral consideration, then we should extend moral consideration to some invertebrate animals.

To address this issue, section 1 will clarify the two main concepts that should be considered in order to assess whether invertebrates can suffer, namely, nociception and pain. Section 2 will show the fundamental problem that arises when it comes to attributing any kind of subjective experience to other individuals, that is, that there will never be any direct proof for its existence. The problem of solipsism, therefore, forces us to appeal to indirect evidence, such as behavior. Thus, lest we display a speciesist prejudice, the same criteria for the identification of sentience needs to be applied to individuals of different species. Section 3 will present the criteria which can be used in order to infer that, if the experience of pain is attributed to other vertebrates, it should also be attributed to invertebrates. The moral relevance of the experience of pain

1 The author wants to express his gratitude to Oscar Horta for his valuable time and suggestions, as well as to the anonymous reviewers of the journal for their corrections. 
will be dealt with in section 4 . Finally, it will be concluded that there are solid arguments to claim that at least a large number of invertebrates have the capacity to experience pain and, hence, moral consideration should be granted to them.

\section{Nociception and the experience of pain}

Several factors need to be considered to address the question whether invertebrates suffer. It is relatively uncontroversial that nociception is one of them. As defined by Smith, nociception is "the capacity to detect and respond to noxious or aversive stimuli" (Smith, 1991, p. 26); that is, beings with nociception are endowed with a sensory system which allows them to react to external threats by showing reflex movements. An example is the violent reaction, aimed at evasion, of insects when a needle at high temperature is moved closer to their antenna (Wigglesworth, 1980).

The presence of nociception has been established in invertebrates such as snails (Wigglesworth, 1980), fruit flies (Tracey et al., 2003), earthworms (Elwood, 2011), leeches (Broom, 2013), mollusks (Crook \& Walters, 2011), octopuses (Mather, 2001), or nematodes (Wittenburg \& Baumeister, 1999). In fact, as Feinberg and Mallatt (2016) defend, nociception was even present in the "Cambrian Explosion" in vertebrate ancestors. However, as Mather (2001) clarifies, nociception is a necessary but not sufficient condition for the existence of subjective experiences in general, and for the experience of pain in particular. In fact, nociceptive responses may even occur without subjective experience in the case of human beings (Crook \& Walters, 2011).

Pain has been defined as "an internal awareness, coupled with a negative emotional state or feeling, that results from perception of actual or potential tissue damage" (Elwood, 2011, p. 176). In this sense, pain produces suffering as a negative experience for the subject who feels it. Due to this, on those occasions when suffering is dealt with in this work, the possibility of experiencing pain will be assumed. However, it should be clarified that pain and suffering are not two necessarily coimplicated phenomena. While all pain involves a certain amount of suffering, it does not happen the other way around. Not all suffering, understood as a "negative emotional state" (Morton \& Hau, 2002, p. 459), entails the experience of pain.

Pain implies not only a behavioral reaction to noxious stimuli, but an awareness of those stimuli. Although both have an evolutionary 
purpose, that of behavioral reactions to noxious stimuli is to protect the individual from immediate damage, while developing awareness of noxious stimuli helps to protect the individual from hypothetical future damage. The latter would be the result of the conjunction of memory with learning about the ways to avoid situations which caused the original pain (Bateson, 1991). Nevertheless, the presence of nociception does not necessarily entail the presence of consciousness, even though it suggests it. Other indicators that allow the attribution of subjective experience to an individual will be examined in this paper. Prior to that examination, it is necessary to deal with one of the key premises on which the argument this paper defends rests.

\section{The problem of the attribution of subjective experiences}

The problem of the attribution of subjective experience could be outlined as follows: we cannot be absolutely certain about how others feel their own mental experiences (Nagel, 1974), or about whether these experiences exist at all (Hyslop, 2014 [2005]). Because of this, although most of those who deal with the issue of invertebrate sentience assign it to human beings, this is ultimately beyond demonstration $(\mathrm{Ng}, 1995$, p. 270). Understanding that, sentience presupposes some degree of consciousness, since it is the capacity to have positive and negative experiences (Lockwood, 1988). In this paper, sentience is equated with phenomenal consciousness as "the qualitative, subjective, experiential, or phenomenological aspects of conscious experience, sometimes identified with qualia" (Allen \& Trestman, 2016 [1995]).

Therefore, if the problem of solipsism is taken as a reference, only experimental and theoretical criteria can be used as a basis for the assumption of subjective experiences in other entities (Lockwood, 1989). Faced with the impossibility of "entering" the mental contents of other minds, a third-person methodological perspective is required (Dennett, 1991). Thus, the criteria considered in this paper will be neurophysiological and behavioral evidence. Merely the fact of belonging to one species or another cannot constitute a guideline per se to assume that the criteria to assess whether some beings are sentient vary depending on the species (Horta, 2010b).

In relation to the aforementioned problem of solipsism, we find the well-known "argument-by-analogy" (Sherwin, 2001), a first argument developed to determine which entities have subjective experiences. According to it, if a particular behavior is observed as a result of an 
electric shock in a mammal and we infer that this individual felt pain, for example, then ceteris paribus we should make the same inference in the case of those invertebrates who react in an analogous way: "we should either reject the argument by analogy for both or accept for both" (Elwood et al., 2009, p. 129). This criterion should not be conclusive, however, as it is possible that some animals feel pain without expressing it (cfr. Dawkins, 2001). For instance, from the fact that a Spartan warrior did not express pain, the inexistence of such pain cannot be deduced. Therefore, even though behavior can be an indicator of sentience, other criteria need to be considered in order to infer which individuals possess subjective experiences.

\section{Criteria to attribute subjective experiences}

Because the study of animal cognition has been addressed by different disciplines, this article focuses on the two most representative criteria. These criteria are the observational, followed for example by ethologists, and the neurophysiological, followed by psychologists (Andrews, 2016). In addition to what has been said in section 1, considerations about the behavioral criterion will be included in section 3.3.

\subsection{Neurophysiological structure}

Barron and Klein (2016a, 2016b), as well as Merker (2007), argue that the most basic kind of consciousness is caused by the activity of human midbrain and basal ganglia. This is backed by the cases of patients who have some degree of consciousness after suffering serious cortical damage, as well as by experiments linked to anesthesia (Barron \& Klein, 2016b). Rather than the "phenomenal consciousness", from which the experience of pain emerges (Barron \& Klein, 2016b), self-consciousness would be the kind of awareness associated with the cerebral cortex (Damasio, 1999). Apart from Barron and Klein, or Merker, other authors, such as Damasio and Carvalho (2013) and Mashour and Alkire (2013), have supported this idea in several works. Despite the differences between the neurophysiological architecture of vertebrates, which have midbrain, and the brain of invertebrates, the existence of a functional analogy between them is possible. Thus, for example, provided that a function of the midbrain in vertebrates is the integration of sensory information for the sake of spatial orientation, this same function is carried out by the nervous system of insects (Barron \& Klein, 2016a, 
2016b). As in vertebrates, there is evidence that this spatial configuration by insects implies certain subjectivity, considering that the filtering of sensory information is selective depending on the relevance that this may have for the choices made by the subject, as in the case of bees (Paulk et al., 2014). The spatial representation of the environment is, therefore, "subjective" and "egocentric" in both vertebrates and invertebrates:

As we have argued, processing of this kind supports the capacity for a subjective experience of the environment. Processing in the insect brain is unified to a similar degree, for similar reasons. Hence, we propose that the insect brain can also support a capacity for subjective experience (Barron \& Klein, 2016a, p. 8).

The existence of natural opioids and analgesics in the nervous system of invertebrates is another neurophysiological type of proof for their possession of subjective experiences, specifically pain (Knutsson, 2016). It is known that natural opioids have the function, among others, of modulating pain in order to reduce the way it is felt (Elwood, 2011). For this reason, Rollin says that "the very existence of endogenous opiates in animals is powerful evidence that they feel pain" (1998, p. 154). Earthworms constitute an example of invertebrates who have been reported to possess natural opioids ( $\beta$-endorphins and enkephalins) whose goal is directly related to the regulation of pain (Lockwood, 1987; Smith, 1991), particularly as analgesics. Similarly, the artificial injection of another kind of analgesics, like morphine, produces an analogous effect in vertebrates and invertebrates. Generally, this effect is expressed with behaviors such as a lesser effort to avoid the sources of pain, as shown in snails (Kavaliers et al., 1983). Related to the similarity between the physiological changes associated to the experience of pain in vertebrates and invertebrates, we can also emphasize pupil dilatation, changes in blood and respiration flow rates, and stress or relative changes in the endocrine system (Elwood et al., 2009; Elwood, 2011). In the light of this evidence, some researchers have already claimed the use of analgesics and anesthetics in research with invertebrates (Lockwood, 1987, 1988; Crook \& Walters, 2011). 


\subsection{Common origins}

As it has been defended by Feinberg and Mallatt (2016), the origin of consciousness dates back to the "Cambrian Explosion" that occurred approximately 500 million years ago. Although the first vertebrates, which had a complex nervous system, began to emerge at that time, they did not appear spontaneously. Vertebrates and invertebrates (namely, arthropods) share a common bilaterian ancestor (a type of worms). According to Feinberg and Mallatt, predation is the main reason why arthropods (as predators) and vertebrates began to evolve independently: "During the Cambrian explosion, two of the most mobile clades of animals followed this path of ever improving sensory systems: the arthropods and the vertebrates" (2016, p. 64). Thus, although the greater genetic potential of vertebrates, their "genomic quadrupling" (2016, p. 67), was the difference with respect to the evolution of invertebrates, the reason for the emergence of consciousness is explained, in both vertebrates and invertebrates, by the sensorial improvements.

\subsection{Cognitive capacities}

It has been already discussed that the evolutionary usefulness of pain experience does not seem to be other than making individuals remember it so that they can avoid possible sources of painful experience in the future (observably, it can also be useful to avoid a source of pain immediately). In order to achieve this aim, both memory and the capacity to avoid the source of pain are necessary. As a result, only those entities that have such characteristics may be sentient, given evolutionary logic.

Memory has been extensively investigated in some invertebrates such as bees (Menzel et al., 2005), which are able to configure a mind map of their environment, to communicate about it - through their wellknown "dance" - and to make deductions from it (Carruthers, 2007). Sømme says in his report on the sentience and pain in invertebrates that "after three visits to a source of sugar, a foraging bee will remember the place forever" (2005, p. 25). Additionally, the mnemonic abilities of other invertebrates, such as cephalopods, have been documented (Mather, 2001).

Closely related to memory there is the ability to escape from a source of harm. In the case of crustaceans, some experiments have shown how 
crabs can recognize the sources of negative experiences suffered in the past. In one of these experiments, after moving the crabs from a dark to an illuminated compartment they receive an electric shock. After one minute they are returned to the dark compartment. With only one trial, the crabs are unwilling to return to the illuminated compartment after 3 hours (Elwood et al., 2009). When they have undergone this process several times, the crabs display this behavior until up to 24 hours later. Similar investigations have been carried out with fruit flies (Yarali et al., 2008), cockroaches or ants (Broom, 2013), and lobsters (Elwood et al., 2009). The results of this research concerning memory and painavoidance learning provides solid reasons to conclude that, if we accept that vertebrates experience pain, the same must be concluded in the case of at least some invertebrates.

\subsection{Some objections}

The conclusion presented above has met with criticism from some authors due to the physiological differences between humans and invertebrates. The small size of the brains of invertebrates, as well as the simplicity of their nervous system, are often mentioned as arguments against it.

Human brains may have around 86 billion neurons (Azevedo et al., 2009), which may be more than 100,000 times more neurons than certain insects (Tomasik, 2016d [2015]). Bees, which are among the insects with greater neuronal systems, have approximately only one million neurons (Menzel \& Giurfa, 2001). Hence, if there is a proportional relationship between brain size, or number of neurons, and consciousness, then it will be true that the above conclusions are incorrect. It would be hard to believe that invertebrates, especially smaller insects, can be conscious of pain and thus experience suffering.

However, the existence of a necessary relationship between the size of a brain, or the number of neurons per se, and the complexity of its functioning is unclear (Broom, 2003; Tomasik, 2016d [2015]; Barron \& Klein, 2016a). As happens in the case of bees, very small brains can produce complex behaviors, such as their famous dance. In fact, studies such as the one carried out by Chittka and Niven (2009) argue that what really matters when it comes to assess the capabilities of a brain are neural circuits, and not so much the mere size. These authors suggest that a greater number of neurons in certain regions of the brain can 
produce a variation in their functioning, for example in the sensory systems. However, from the previous assertion it cannot be inferred that brains with a lesser neuronal density cannot develop these functions. According to these studies, each neuron of an insect could work as a kind of "supercomputer" (Feinberg \& Mallatt, 2016, p. 184), equating its potential with several vertebrate neurons. In consequence, there is no proportional relationship between brain size and ability to be conscious. As Darwin said, "due to the wonderfully diversified instincts, mental powers, and affections of ants," the brain of one of them "is one of the most marvelous atoms of matter in the world, perhaps more so than the brain of man" (Darwin, 1871, qtd. in Chittka \& Niven, 2009, p. R995).

In the same vein, it has also been argued (cfr., for example, Walter, 1983) that invertebrates cannot be conscious as they lack a central nervous system like the one of vertebrates. However, this objection can be questioned since the same function can be caused in different individuals with divergent morphologies (cfr. Lockwood, 1988). Just as the possession of an identical visual system to that of humans is not a conditio sine qua non for the attribution of the sense of sight to other individuals, including invertebrates, neither does the central nervous system have to be completely homogeneous (Elwood, 2011).

Thus, to summarize, the following criteria for the attribution of the experience of pain to other entities, including invertebrates, have been considered here: i) the presence of nociception, together with its behavioral responses, and ii) the possession of a suitable neurophysiological structure. Related to these criteria are: iii) the effects derived from opioids; iv) the possession of certain cognitive capacities, such as memory and pain-avoidance learning, and v) the common origins of consciousness.

The aforementioned objections, in addition to that one which highlights those behaviors of invertebrates which do not adapt to painful experiences, seem to lead towards a different understanding of the experience of pain in invertebrates in relation to vertebrates. Some examples are grasshoppers, which continue to feed despite being devoured by a mantis, or insects which are not perturbed by the amputation of one of their limbs (Smith, 1991). We are talking about the degree and way in which these experiences occur. Thus, it should be acknowledged that the arguments provided against the named objections only underpin the existence of consciousness in invertebrates, namely the experience of pain, but do not provide information about 
either the way in which it is produced, or the degree of its intensity. For these reasons, it should be accepted that the previous objections compel us to talk about consciousness in some invertebrates in a weak sense; that is, as possessors of a "primary consciousness", "I consciousness" (Barron \& Klein, 2016b), or "phenomenal consciousness" (Block, 1991). In addition, the above criteria do not allow attributing that consciousness to all invertebrates, but only to some, mainly arthropods and cephalopods. ${ }^{2}$ On the contrary, some others, like sponges, do not seem to fulfill any of these requirements, so they constitute a type of invertebrate without consciousness. Despite this, the conclusion that can be drawn from this section remains valid. There are solid reasons to hold that, if the experience of pain is conferred to vertebrates other than ourselves, it must also be conferred to some invertebrates.

\section{The ethical relevance of suffering}

Most animal ethicists have argued that the capacity to feel pain is at least a sufficient condition-if not a necessary one, as well-for moral consideration (Singer, 1975; Regan, 1983; Sapontzis, 1987; Pluhar, 1995; Francione, 2000; Cavalieri, 2001; Dunayer, 2004; Horta, 2010b). At this point it should be clarified that, although pain is an extremely effective mechanism for survival, this is completely external to its relevance as a criterion for moral consideration. This difference can be seen with an example: someone can be thankful for the experience of the pain produced in his hand because this makes him aware of the fact that he is resting that hand on a burning board. But the "moral utility" of such suffering lies in the fact that it avoids even greater pain. In the same way, it may be correct to inflict a certain pain on a subject, for instance by pulling a tooth, as long as it avoids a greater pain. If the moral relevance of our acts lies in the positive or negative effects that they will have on other individuals, and whether they could be sentient due to this, then acts that affect sentient beings must be morally relevant. If this is understood this way, we will realize that every sentient being must be morally considered, which implies that their interests must be taken into account directly, not in an instrumental way (Bernstein, 1998).

2 One of the works cited (Feinberg \& Mallatt, 2016) comes to a similar conclusion. 
Given the nature of positive and negative experiences, we do not usually believe that both can be taken symmetrically (Griffin, 1979). This idea is supported by those who defend a negative consequentialism theory. It is highly counterintuitive to think that the suffering experienced in Auschwitz, for example, by a Jew, could be compensated by some amount of future pleasure (Pearce, 2010). It is also counterintuitive that somebody could consider positive the creation of happy beings, either two (Tomasik, 2016a [2015]) or an indeterminate number (Longueira, 2011), in exchange for the creation of one who experiences extreme suffering during all their lifetime. This idea could also be supported by taking the "Law of Hedonic Asymmetry" of Frijda (1988) as a reference. According to it, negative experiences are characterized by their greater degree and temporal persistence with respect to positive ones, which tend to disappear quickly.

As a result, among other reasons, of the reproductive strategy followed by invertebrates, predation or parasitism (Faria, 2016), an enormous number of invertebrates which are born have only the opportunity to have negative experiences (Horta, 2015). Therefore, from the perspective of negative consequentialism, a first ethical measure to reduce the suffering of invertebrates is to prevent their birth. A successful measure of this type implemented, although not for the reasons stated above, consists in the release of mosquitoes with low reproductive capacity whose very few offspring will also have these difficulties for reproduction (Zheng et al., 2019). Nevertheless, the realization of such measures for ethical purposes should always be preceded by a scrupulous study about the consequences that will occur in the short, medium and long term, which is not a simple task.

Nevertheless, due to the current social and cultural context, there is a normative prescription prior to the previous one, which is the overcoming of speciesism. As long as this does not happen, no action (such as the one already mentioned) will be carried out in a way which has strong repercussion. Beyond these two measures, there are some others that should be considered, such as feeding from invertebrates (Tomasik, 2016c), or the use of materials such as silk (Tomasik, 2016b). Ultimately, in view of what has been seen in this paper, we must avoid prima facie any practice that could harm invertebrates.

As it has been shown above, although the degree and way in which painful experiences are felt is unclear, the ethical implications of their existence remain. As argued by Horta (2010a) and Knutsson (2015), even 
if we consider that the degree of sentience of insects is lower than the one of mammals, this possibility could not be a minimal risk (Knutsson, 2015). An important reason for this is the large number of individuals who could be in this situation. ${ }^{3}$ Even if the suffering of mammals was significantly stronger than that of insects, the incredible number of the latter would balance the suffering felt by the first ones. Consequently, there is a moral duty to take this into consideration, and act in accordance with the suggestions mentioned above.

\section{Conclusion}

If we accept that vertebrates have the capacity to experience pain, then the available evidence strongly indicates that it should be accepted in the case of many invertebrates. The inability to access the minds of others forces us to consider indirect criteria alone, such as neurophysiological or behavioral criteria. As previously mentioned in this paper, numerous studies show how the neurophysiological structure of some invertebrates, such as insects or cephalopods, can produce the phenomenal consciousness necessary to experience pain. The behavior of many of these arthropods or mollusks reinforces this idea. However, by virtue of these criteria, we cannot attribute consciousness to other invertebrates, such as those belonging to the phyla of the Polifera (sponges). Either way, although the degree in which pain is experienced by invertebrates is unclear, the total number of invertebrates in the world means that their suffering is a huge ethical problem. This is due to the fact that belonging to particular species cannot be taken per se as a reason for discrimination, in a similar way to what happens with gender or skin color. A moral differentiation between distinct beings can only be made on the basis of non-arbitrary criteria. Following the premises which are usually accepted by animal ethicists, this paper has focused on the consequences that are more rarely remarked, which are the duty to grant moral consideration to invertebrates, as well as all the need that the moral agents that take this moral consideration into account act according to that idea.

3 Without considering the rest of invertebrates with the capacity to experience pain, it is estimated that there are between $10^{18}$ and $10^{19}$ insects on the planet (Horta, 2010b; Knutsson, 2015). 


\section{Bibliography}

Allen, C. \& Trestman, M. (2016 [1995]). Animal Consciousness. The Stanford Encyclopedia of Philosophy. E. N. Zalta. (ed.). URL: https:// plato.stanford.edu/entries/consciousness-animal/.

Andrews, K. (2016 [2008]). Animal Cognition. The Stanford Encyclopedia of Philosophy. E. N. Zalta. (ed.). URL: https://plato.stanford.edu/ entries/cognition-animal/.

Azevedo, F., Carvalho, L., Grinberg, L., Farfel, J. M., Ferretti, R., Leite, R., Filho, W. J., Lent, R. \& Herculano-Houzel, S. (2009). Equal Numbers of Neuronal and Nonneuronal Cells Make the Human Brain an Isometrically Scaled-up Primate Brain. Journal of Comparative Neurology, 513, 532-541.

Barron, A. \& Klein, C. (2016a). Insects Have the Capacity for Subjective Experience. Animal Sentience, 100.

(2016b). What Insects Can Tell Us About the Origins of Consciousness. Proceedings of the National Academy of Sciences, 113, 4900-4908.

Bateson, P. (1991). Assessment of Pain in Animals. Animal Behaviour, 42, 827-839.

Bernstein, M. (1998). On Moral Considerability: An Essay on Who Morally Matters. Oxford University Press.

Block, N. (1991). Evidence against Epiphenomenalism. Behavioral and Brain Sciences, 14, 670-672.

Broom, D. M. (2013). The Welfare of Invertebrate Animals such as Insects, Spiders, Snails and Worms. In A. van der Kemp \& M. Lachance (eds.), Animal Suffering: From Science to Law, International Symposium. (pp. 135-152). Éditions Yvon Blais.

Carere, C., Wood, J. B. \& Mather, J. (2011). Species Differences in Captivity: Where are the Invertebrates? Trends in Ecology and Evolution, 26, 211.

Carruthers, P. (2007). Invertebrate Minds: A Challenge for Ethical Theory. The Journal of Ethics, 11, 275-297.

Cavalieri, P. (2001). The Animal Question: Why Nonhuman Animals Deserve Human Rights. Oxford University Press.

Chittka, L. \& Niven, J. (2009). Are Bigger Brains Better? Current biology, 19, R995-R1008. 
The Suffering of Invertebrates: An Approach from Animal Ethics

Crook, R. J. \& Walters E. T. (2011). Nociceptive Behavior and Physiology of Molluscs: Animal Welfare Implications. ILAR Journal, 52, 185-195.

Damasio, A. (1999). The Feeling of What Happens: Body and Emotion in the Making of Consciousness. Harcourt Inc.

Damasio, A. \& Carvalho, G. B. (2013). The Nature of Feelings: Evolutionary and Neurobiological Origins. Nature Reviews Neuroscience, 14, 143152.

Darwin, C. (1871). The Descent of Man, and Selection in Relation to Sex. John Murray.

Dawkins, M. S. (2001). Who Needs Consciousness? Animal Welfare, 10, 19-29.

Dennett, D. (1991). Consciousness Explained. Little, Brown and Company. Dunayer, J. (2004). Speciesism. Ryce.

Elwood, R. W. (2011). Pain and Suffering in Invertebrates? Institute of Laboratory Animal Resources Journal, 52, 175-184.

Elwood, R. W., Barr, S. \& Patterson, L. (2009). Pain and Stress in Crustaceans? Applied Animal Behaviour Science, 118, 128-136.

Faria, C. (2016). Animal Ethics Goes Wild: The Problem of Wild Animal Suffering and Intervention in Nature. (Doctoral Dissertation). Universitat Pompeu Fabra.

Feinberg, T. E. \& Mallatt, J. M. (2016). The Ancient Origins of Consciousness: How the Brain Created Experience. MIT Press

Francione, G. (2000). Introduction to Animal Rights: Your Child or the Dog? Temple University Press.

Frijda, N. H. (1988). The Laws of Emotion. American psychologist, 43, 349358.

Griffin, J. (1979). Is Unhappiness Morally More Important than Happiness? The Philosophical Quarterly, 29, 47-55.

Horta, O. (2010a). Disvalue in Nature and Intervention: The Fox, the Rabbit and the Vegan Food Rations. Pensata Animal, 34. (2010b). What is Speciesism? Journal of Agricultural and Environmental Ethics, 23, 243-266.

(2015). The Problem of Evil in Nature: Evolutionary Bases of the Prevalence of Disvalue. Relations. Beyond Anthropocentrism, 3, 17-32.

Horvath, K., Angeletti, D., Nascetti, G. \& Carere, C. (2013). Invertebrate Welfare: An Overlooked Issue. Annali dell'Istituto Superiore di Sanità, 49, 9-17. 
Hyslop, A. (2014 [2005]). Other Minds. The Stanford Encyclopedia of Philosophy. E. N. Zalta. (ed.). URL: https://plato.stanford.edu/entries/ other-minds/.

Kavaliers, M., Hirst, M., \& Teskey, G. C. (1983). A Functional Role for an Opiate System in Snail Thermal Behavior. Science, 220, 99-101.

Knutsson, S. (2015). The Moral Importance of Invertebrates such as Insects. (Master's thesis). University of Gothenburg.

(2016). Reducing Suffering among Invertebrates such as Insects. Sentience Politics. URL: https://sentience-politics.org/research/policypapers/invertebrate-suffering/.

Lockwood, J. (1987). The Moral Standing of Insects and the Ethics of Extinction. The Florida Entomologist, 70, 70-89.

(1988). Not to Harm a Fly: Our Ethical Obligations to Insects. Between the Species, 4, 204-211.

(2014). Jeffrey Lockwood on Insect Suffering. An interview by Max Maxwell Brian Carpendale. Essays on Reducing Suffering. URL: http:// reducing-suffering.org/wp-content/uploads/2014/10/lockwoodinsect-suffering.pdf.

Longueira, A. (2011). El sufrimiento animal y la extinción. Ágora: Papeles de filosofía, 30, 43-56.

Mashour, G. A., \& Alkire, M. T. (2013). Evolution of Consciousness: Phylogeny, Ontogeny, and Emergence from General Anesthesia. Proceedings of the National Academy of Sciences, 110, 1035710364.

Mather, J. A. (2001). Animal Suffering: An Invertebrate Perspective. Journal of Applied Animal Welfare Science, 4, 151-56.

Menzel, R. \& Giurfa, M. (2001). Cognitive Architecture of a Mini-Brain: The Honeybee. Trends in Cognitive Sciences, 5, 62-71.

Menzel, R., Greggers, U., Smith, A., Berger, S., Brandt, R., Brunke, S., Bundrock, G., Hülse, S., Plümpe, T., Schaupp, F., Schüttler, E., Stach, S., Stindt, J., Stollhoff, N. \& Watzl, S. (2005). Honey Bees Navigate According to a Map-like Spatial Memory. Proceedings of the National Academy of Sciences, 102, 3040-3045.

Merker, B. (2007). Consciousness without a Cerebral Cortex: A Challenge for Neuroscience and Medicine. Behavioral and brain sciences, 30, 6381.

Morton, D. B. \& Hau, J. (2002). Welfare Assessment and Humane Endpoints. In J. Hau \& G. L. van Hoosier (eds.), Handbook of 
The Suffering of Invertebrates: An Approach from Animal Ethics

Laboratory Animal Science. Volume I: Essential Principles and Practices. (pp. 457-486). CRC Press.

Nagel, T. (1974). What Is It Like to Be a Bat? The Philosophical Review, 83, 435-450.

Ng, Y.-K. (1995). Towards Welfare Biology: Evolutionary Economics of Animal Consciousness and Suffering. Biology and Philosophy, 10, 255285.

Paulk, A. C., Stacey, J. A., Pearson, T. W., Taylor, G. J., Moore, R. J., Srinivasan, M. V. \& Van Swinderen, B. (2014). Selective Attention in the Honeybee Optic Lobes Precedes Behavioral Choices. Proceedings of the National Academy of Sciences, 111, 5006-5011.

Pearce, D. (2010). Why Be Negative? The Hedonistic Imperative. URL: https://www.hedweb.com/negutil.htm.

Pluhar, E. (1995). Beyond Prejudice: The Moral Significance of Human and Nonhuman Animals. Duke University Press.

Regan, T. (1983). The Case for Animal Rights. University of California Press.

Rollin, B. (1998). The Unheeded Cry: Animal Consciousness, Animal Pain, and Science. Iowa State University Press.

Sapontzis, S. (1987). Moral, Reason, and Animals. Temple University Press. Sherwin, C. M. (2001). Can Invertebrates Suffer? Or, How Robust is Argument-by-Analogy? Animal Welfare, 10 (supplement), 103-118.

Singer, P. (1975). Animal Liberation: A New Ethics for Our Treatment of Animals. Random House.

Smith, J. A. (1991). A Question of Pain in Invertebrates. Institute for Laboratory Animal Research Journal, 33, 25-32.

Sømme, L. S. (2005). Sentience and Pain in Invertebrates. Report to Norwegian Scientific Committee for Food Safety. URL: https://www. seafoodnews.com/news/images/norwegianinvertebrate.pdf.

Tomasik, B. (2016a [2015]). Are Happiness and Suffering Symmetric? Essays on Reducing Suffering. URL: http://reducing-suffering.org/ happiness-suffering-symmetric/.

(2016b). Insect Suffering from Silk, Shellac, Carmine, and Other Insect Products. Essays on Reducing Suffering. URL: http://reducingsuffering.org/insect-suffering-silk-shellac-carmine-insect-products/. (2016c). The Cruelty of Eating Snails. Essays on Reducing Suffering. URL: http://reducing-suffering.org/cruelty-eating-snails/. 
(2016d [2015]). The Importance of Insect Suffering. Essays on Reducing Suffering. URL: http://reducing-suffering.org/the-importance-ofinsect-suffering/.

Tracey, D. W., Wilson, R. I., Laurent, G. \& Benzer, S. (2003). painless, a Drosophila Gene Essential for Nociception. Cell, 113, 261-273.

Walter, S. (1983). Animal Thought. Routledge \& Kegan Paul.

Wigglesworth, V. B. (1980). Do Insects Feel Pain? Antenna, 4, 8-9.

Wittenburg, N. \& Baumeister, R. (1999). Thermal Avoidance in Caenorhabditis elegans: An Approach to the Study of Nociception. Proceedings of the National Academy of Sciences, 96, 10477-10482.

Yarali, A., Niewalda, T., Chen, Y.-C., Tanimoto, H., Duerrnagel, S., \& Gerber, B. (2008). Pain Relief Learning in Fruit Flies. Animal Behaviour, 76, 1173-1185.

Zheng, X., Zhang, D., Li, Y., Yang, C., Wu, Y., Liang, X., Liang, Y., Pan, X., Hu, L., Sun, Q., Wang, X., Wei, Y., Zhu, J., Qian, W., Yan, Z., Parker, A. G., Gilles, J. R. L., Bourtzis, K., Bouyer, J., Tang, M., Zheng, B., Yu, J., Liu, J., Zhuang, J., Hu, Z., Zhang, M., Gong, J.-T., Hong, X.-Y., Zhang, Z., Lin, L., Liu, Q., Hu, Z., Wu, Z., Baton, L. A., Hoffmann, A. A. \& Xi, Z. (2019). Incompatible and Sterile Insect Techniques Combined Eliminate Mosquitoes. Nature, 572, 56-61. 